\title{
PERAN MEDIA INSTAGRAM DALAM MEMASARKAN PRODUK FASHION DOLLIES
}

\section{THE ROLE OF INSTAGRAM IN MARKETING FASHION PRODUCT DOLLIES}

\author{
Mochammad Rachmansyah $^{1}$, Lucy Pujasari Supratman ${ }^{2}$ \\ ${ }^{1,2}$ Universitas Telkom \\ Jalan Telekomunikasi Nomor 1, Bandung, Indonesia \\ 1'mrachmansyah87@telkomuniversity.ac.id; ${ }^{2}$ lucysupratman@telkomuniversity.ac.id \\ Diterima tgl. 30/1/2020; Direvisi tgl. 2/6/2020; Disetujui tgl. 2/6/2020
}

\begin{abstract}
Indonesian internet users dominate access to chat services and social media, one of which is Instagram. The business began to enter the medium that is have much audiences. This phenomenon is used by Dollies through Instagram @wearedollies as a product marketing communication medium. This study aims to describe comprehensively the role of social media content in marketing Dollies products via Instagram @wearedollies. The analysis was carried out using marketing mix and promotion mix theory which is connected with the @wearedollies instagram contents. Descriptive qualitative paradigm is used to understand all phenomenons that occured. The result is the Instagram content @wearedollies used all elements of the promotion mix with diverse roles. The content that appeared consists of Instagram profiles, product photos and videos, captions, feedback comments, and direct messages for existence roles, repost and testimonials content for engagement roles, open reseller, discounts, and open orders content for sales roles, as well as endorse and giveaway content traffic roles.
\end{abstract}

Keywords: Instagram, Social Media, Marketing Communication

\begin{abstract}
ABSTRAK
Pengguna internet Indonesia mendominasi akses layanan chatting dan media sosial, salah satunya Instagram. Bisnis pun mulai memasuki ruang yang banyak diminati khalayak tersebut. Fenomena ini dimanfaatkan Dollies melalui instagram @wearedollies sebagai media komunikasi pemasaran produknya. Penelitian ini bertujuan untuk mendeskripsikan secara komprehensif mengenai peran konten media sosial dalam pemasaran produk Dollies melalui instagram @wearedollies. Analisis dilakukan dengan menggunakan teori bauran pemasaran dan promosi yang dikaitkan dengan konten instagram @wearedollies. Paradigma kualitatif deskriptif digunakan untuk memahami rincian fenomena yang terjadi. Hasil dari penelitian ini adalah konten instagram @wearedollies menggunakan seluruh elemen bauran promosi dengan peran yang beragam. Konten yang dimunculkan terdiri dari profil instagram, foto dan video produk, caption, feedback komentar, dan direct message untuk peran eksistensi, konten repost dan testimoni untuk peran engagement, konten open reseller, diskon, dan open order untuk peran penjualan, serta konten endorse dan giveaway untuk peran traffic.
\end{abstract}

Kata Kunci: Peran, Instagram, Pemasaran, Produk Fashion

\section{PENDAHULUAN}

Penggunaan teknologi digital semakin diminati karena memiliki banyak keunggulan pada setiap fiturnya secara praktis dan aplikatif. Perubahan besar ini juga terjadi karena adanya pengaruh besar dari eksistensi internet. Semakin besar penerimaan hingga penggunaan internet oleh setiap orang, maka teknologi digital pun semakin memiliki ruang yang luas untuk semakin berkembang. Penelitian terdahulu (Andika \& Jovita, 2018; Fauzi \& Mileva, 2018; Nadya, 2016) menyokong argumentasi tersebut bahwa peranan digital marketing terwujud dengan baik apabila didukung dengan pemahaman perilaku konsumen yang sesuai dengan perkembangan teknologi yang terbaru.

Fenomena ini pun dimanfaatkan oleh hampir seluruh pelaku ekonomi, dari produsen dan distributor besar hingga unit usaha mikro, kecil, dan menengah karena melihat pangsa pasar daring 
yang semakin melejit eksistensinya. Dengan memanfaatkan media sosial yang termuat dalam internet, banyak pelaku usaha yang mencoba memaksimalkan ruang daring tersebut sehingga menimbulkan istilah baru bagi aktivitas bisnis, yaitu komunikasi pemasaran melalui platform digital.

Media sosial merupakan sebuah media online, dengan para pengguna yang dapat dengan mudah berpartisipasi, berbagi, dan menciptakan isi meliputi blog, jejaring sosial, wiki, forum dan dunia virtual. Blog, jejaring sosial, dan wiki merupakan bentuk media sosial yang paling sering digunakan oleh masyarakat di seluruh dunia. Media sosial pun sangat mendukung interaksi sosial dan media sosial menggunakan teknologi berbasis internet yang mengubah komunikasi menjadi dialog interaktif tanpa mengenal batasan ruang dan waktu.

Media sosial merupakan proses kolaborasi dalam membentuk, menyebarkan, mengubah, dan menghancurkan informasi (Evans, 2012). Sosial media dapat mengumpulkan sejumlah informasi dan pengetahuan, namun kebenaran dari hal tersebut perlu diperhatikan secara mendalam. Oleh karena itu, sosial media lebih berperan efektif dalam tindakan pertisipasi atau bersosialisasi dan mempengaruhi khalayak, bukan memberikan pernyataan atau pun mengontrol mereka. Peluang partisipasi dalam sosial media dapat menimbulkan pengaruh dan membantu mencapai tujuan bisnis dan pemasarannya.

Proses pembelian dalam gambar pembelian klasik menurut Evans (2012) adalah sebagai berikut:

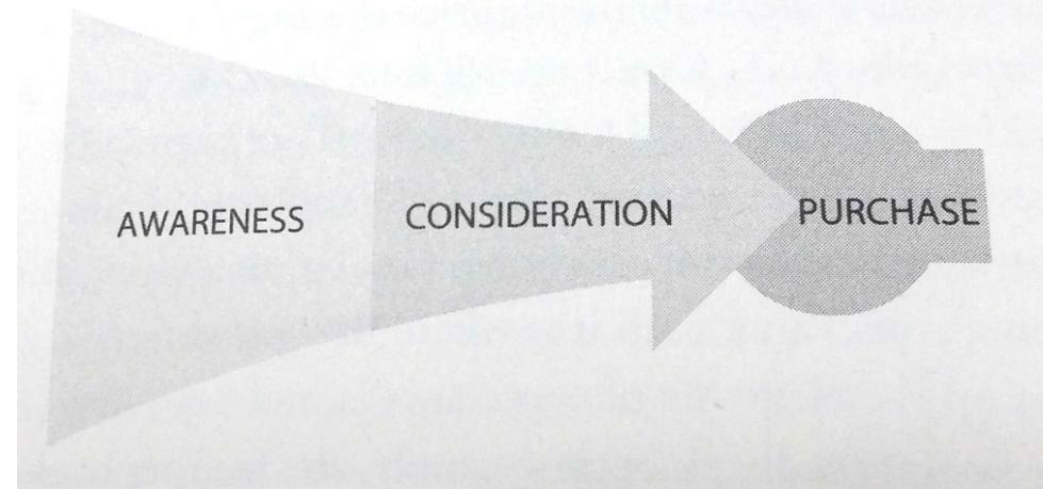

Gambar 1. The Classic Purchase Funnel (Evans, 2012)

Dalam penelitian ini, jika dikaitkan dengan teori perputaran tanggapan sosial (Evans, 2012), pemasaran digital yang dilakukan oleh Dollies adalah dalam bentuk media sosial. Menurut Taiminen, H.M., \& Karjaluotom (2015), penggunaan media sosial bagi para konsumen yang telah membeli produk tersebut akan memberikan opini atau pandangan mereka dalam bentuk pernyataan di media sosial. Shuqair, S., \& Cragg (2016) menjelaskan dalam temuan penelitiannya bahwa konten Instagram memilki efektifitas dalam mengubah persepsi pengunjung dan mempengaruhi perilaku pembelian bagi suatu produk/jasa yang dipromosikan. pemirsa Media sosial sangat memungkinkan konsumen untuk selalu terlibat terhadap suatu produk atau merek secara lebih dalam dan luas daripada sebelumnya. Penjual pun harus melakukan banyak cara untuk mendorong konsumen agar bersedia terlibat aktif secara produktif. Feedback semacam inilah yang akhirnya mampu meningkatkan kembali pengembangan perusahaan yang lebih baik dan besar lagi.

Mengingat perkembangannya yang sangat cepat, sosial media dapat menjadi media paling strategis bagi pemasaran sebuah merek atau produk suatu perusahaan untuk menjangkau konsumen di masa mendatang. Hal inilah yang dimanfaatkan oleh banyak bisnis di Indonesia, salah satunya Dollies melalui media sosial instagramnya, yaitu @wearedollies. Dollies merupakan bisnis pakaian wanita yang memiliki lebih dari 662.000 pengikut Shopee-nya dan menjadi pengguna menjadi 
salah satu online shop terlaris dari kategori pakaian impor wanita di Indonesia. Ditambah dengan performa pelayanan yang sangat baik, akun Shopee Dollies yang bernama “@wearedollies" mendapatkan penghargaan berupa predikat Star Seller dari Shopee. Performa positif tersebut tidak terlepas dari peran konten media sosial Instagram yang menjadi media komunikasi pemasarannya, @wearedollies yang merupakan salah satu online shop terbaik dan terkenal bila dilihat dari banyaknya rekomendasi yang merujuk pada @wearedollies dalam \#FORUM Rekomendasi Online Shop Blouse Hijab yang Murah dan Bagus! Share Your Online Shop! oleh beautynesia.id.

Tabel 1. Data Instagram Online Shop Yang Direkomendasikan dalam Forum beautynesia.id

\begin{tabular}{clcc}
\hline No & \multicolumn{1}{c}{ Akun Instagram } & $\begin{array}{c}\text { Branding } \\
\text { Produk }\end{array}$ & Followers \\
\hline 1 & @ mayoutfit & Lokal & 1.000 .000 \\
2 & @ heaven_lights & Lokal & 1.000 .000 \\
3 & @ wearedolliesa & Impor & 662.000 \\
4 & @ oclo.official & Lokal & 596.000 \\
5 & @ diamore_id & Lokal & 553.000 \\
6 & @ clo_id & Lokal & 473.000 \\
7 & @ butikaluna & Lokal & 466.000 \\
8 & @ nuna_id & Lokal & 321.000 \\
9 & @ pulchragallery & Lokal & 294.000 \\
10 & @ilikethishopwithlove & Impor & 163.000 \\
11 & @ rosellacloset & Lokal & 112.000 \\
\hline
\end{tabular}

Sumber: beautynesia.id (2019) Dikkses 10 Maret 2019

Berdasarkan tabel 1.1 di atas, dengan jenis produk yang sama, yaitu blouse, bottom, knit, outer, dan dress untuk wanita serta berdasarkan rekomendasi pada forum beautynesia.id, followers @wearedollies menempati posisi ketiga terbanyak. Sedangkan berdasarkan jenis branding produk impor, @wearedollies berada di posisi teratas dalam segi jumlah followers jauh melampaui pesaingnya @ilikethishopwithlove yang hanya memiliki 163.000 followers.

Pada online shop-nya, Dollies menerapkan satu fokus penggunaan media sosial permasaran saja yaitu Instagram. Optimalisasi pemasaran digital inilah yang kemudian menjadikan penjualan Dollies semakin cepat berkembang pesat dan diminati konsumen yang semula hanya berada di wilayah Bandung, kini sudah menjangkau seluruh wilayah di Indonesia. Asanbekova, M., \& Maksudunov (2018) dan Germon, R., Sokolova, K \& Bami (2017) menguatkan betapa efektifnya media sosial instagram dalam memasarkan produk di jejaring sosial. Penelitian yang mereka lakukan difokuskan pada pengembangan strategi pemasaran iklan melalui Instagram. Hasil penelitian tersebut berpengaruh kuat pada peningkatan konsumen dengan stategi pemasaran yang mengevauasi jumlah like dan comment. Strategi pemasaran dalam Instagram ini berbeda dengan yang dilakukan Dollies. Dollies memiliki strategi pemasaran digital tertentu untuk meningkatkan promosi dan penjualannya terutama dari sisi konten media sosial Instagram. Distributor barang yang dijual Dollies semula hanya terpaku pada barang impor yang masuk di Pasar Tanah Abang. Kemudian, terobosan pun dilakukan Dollies dengan cara memutus alur distribusi melalui distributor di Pasar Tanah Abang dengan melakukan impor langsung dari produsennya di Tiongkok dengan pertimbangan maksimalisasi margin laba dan kustomisasi pilihan barang. 


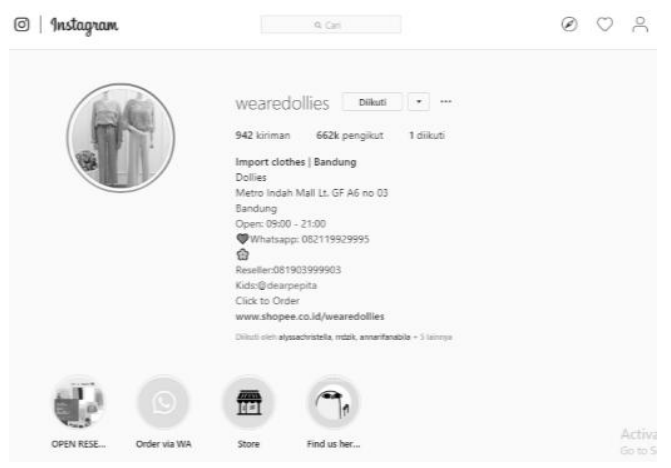

Sumber: Instagram.com/@wearedollies (2019)

Gambar 1. Beranda Instagram @wearedollies

Akun instagram @wearedollies memiliki cara tersendiri dalam mengelola konten media sosial instagramnya sebagai media komunikasi pemasaran produk. Hal ini yang kemudian memiliki peran penting bagi adanya pertambahan luasan jangkauan konsumen dan brand awareness dari para konsumen.

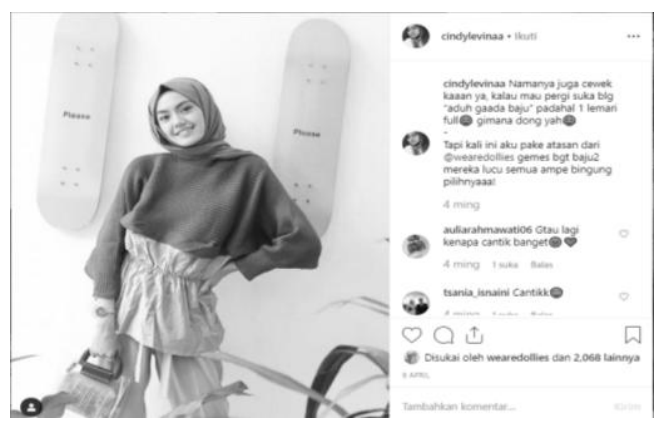

Sumber: Instagram.com/@wearedollies (2019)

Gambar 2. Konten Endorse @ wearedollies oleh Selebgram @ cindylevina

Pada gambar 2 di atas adalah salah satu konten unggahan foto produk @wearedollies oleh endorser@cindylevinaa yang merupakan selebgram di beranda instagram @ wearedollies. Dengan followers@cindaylevinaa yang berjumlah 271.000 (instagram.com, diakses pada tanggal 8 Mei 2019), tentunya kemudian akan memunculkan lalu lintas akses terhadap akun instagram @ wearedollies. Kemudian masih banyak lagi konten media sosial yang dimunculkan sebagai media pemasaran produk Dollies melalui instagram yang memicu pertumbuhan bisnis @ wearedollies terutama dalam aspek pemasaran produk Dollies. Berdasarkan latar belakang dan fokus penelitian di atas maka identifikasi masalah pada penelitian ini adalah bagaimana strategi komunikasi pemasaran@wearedollies dalam mengelola konten Instagram?

\section{METODE PENELITIAN}

Metode penelitian dalam penelitian ini menggunakan pendekaran studi kasus. Pendekatan ini dipergunakan karena terdapat keunikan dalam cara memasarkan produk Dollies menggunakan media sosial Instagram. Keunikan tersebut berupa bentuk eksistensi publisitas promosi produk yang bertema ramah lingkungan, islami, syiar dakwa dalam konten foto serta video di instagram. Selain itu, konten promosi produk-produk tersebut dibuat secara model katalog yang sangat memperhatikan nilai estetika modernitas ketimuran dalam proses pembuatan kontennya.

Teknik pengumpulan data yang digunakan dalam penelitian adalah observasi, wawancara, dan dokumentasi. Observasi tahap awal dilakukan dengan mengamati setiap posting/unggahan yang diunggah oleh@wearedollies. Setelah itu, observasi tahap kedua dilanjutkan di kantor Dollies 
Jalan Sumbersari, Arcamanik, Kota Bandung untuk melakukan pengamatan langsung terhadap tim pemasaran Dollies saat melakukan modifikasi konten media sosial Instagram @wearedollies dalam pemasaran produk Dollies. Selain itu, wawancara juga dilakukan pada informan kunci pada pemillik Dollies yang bernama Sofyana Hambali., S.M., M.B.A. Pemilik Dollies tersbut memiliki kewenangan penuh dan tanggung jawab dalam pembuatan konten media sosial Instagram @ wearedollies. Selanjutnya, wawancara dilakukan pada informan Pendukung, yaitu Nurul Faida sebagai Manajer Pemasaran. Tugas manajer pemasaran Dollies adalah melakukan tugas pembuatan konten media sosial Instagram @ wearedollies. Kemudian, data-data wawancara tersebut divalidasi dengan mewawancarai informan pakar, yaitu Dr. Mohamad Toha, S.T., M.B.A sebagai ahli strategi bisnis dan manajemen pemasaran.

Proses pengumpulan data dengan pendekatan triangulasi digunakan peneliti selain untuk mengumpulkan data tetapi juga untuk menguji kredibilitas data yang ada dari berbagai sumber tersebut. Menurut Stainback dalam Sugiyono (2017), teknik triangulasi dalam penelitian kualitatif bertujuan bukan untuk mencari kebenaran tentang fenomena, tetapi lebih pada peningkatan pemahaman peneliti terhadap apa yang telah ditemukan. Kebenaran data dimaksud valid atau tidak, maka harus dibandingkan dengan data lain yang diperoleh dari sumber lain. Oleh karena itu, peneliti mengadakan pengecekan terhadap validasi data yang telah diperoleh dengan mengonfirmasi antara data/informasi yang diperoleh dari sumber lain, yaitu marketing manager Dollies yang berkaitan dengan. Kemudian peneliti melakukan verifikasi data melalui member checking, yaitu validasi data dalam penelitian kualitatif yang bertujuan untuk mengetahui akurasi hasil penelitian. Proses ini dapat dilakukan dengan membawa kembali laporan akhir atau deskripsideskripsi ke hadapan partisipan untuk mengecek apakah laporan, deskripsi, atau tema tersebut sudah akurat. Sejalan dengan itu, Wiliam Wiersma (Sugiyono, 2017) menerangkan bahwa member checking adalah proses pengecekan data yang diperoleh peneliti kepada pemberi data. Proses ini bertujuan untuk mengetahui seberapa jauh data yang diperoleh sesuai dengan apa yang diberikan oleh pemberi data. Dengan demikian, proses member checking dalam validasi data penelitian ini ditujukan untuk mengungkapkan kesesuaian informasi atau data yang diperoleh peneliti dari para informan selama proses penelitian berlangsung, apakah sesuai dengan pendapat mereka sehingga data yang disusun dapat divalidasi sebagai hasil akhir dari penelitian. Proses yang dilakukan dalam penelitian ini ditempuh dengan cara peneliti melakukan pengunjungan langsung secara pribadi dan melakukan diskusi lepas dengan informan, khususnya pemilik Dollies dan manajer pemasaran @wearedollies, mengenai kesesuaian pendapat yang telah diungkapkan oleh informan saat observasi dan wawancara berlangsung dengan yang peneliti dokumentasikan. Tujuan diskusi lepas tersebut adalah menyesuaikan data-data yang telah dituliskan oleh peneliti. Dalam penelitian ini, hal-hal yang direduksi adalah hasil observasi maupun wawancara yang berkaitan dengan konten media sosial Instagram @ wearedollies dan pemasaran produk Dollies. Hal-hal tersebut dilakukan peneliti untuk memudahkan peneliti dalam melakukan penyajian data untuk kemudian dilakukan penarikan kesimpulan dari hasil penelitian.

\section{HASIL DAN PEMBAHASAN}

Foto produk dalam bentuk katalog pada feeds instagram @wearedollies menunjukkan produk Dollies memiliki karakter tersendiri yang tidak terlepas dari estetika yang diciptakan dari proses pembuatan konten. Manajer Pemasaran Dollies mengungkapkan bahwa konsep foto yang digunakan adalah untuk memberi kesan hidup yang berujung pada penguatan eksistensi instagram $@$ wearedollies. Konten media sosial instagram @ wearedollies sangat berperan dalam pemasaran produk Dollies. Dengan konten yang beragam, peran yang dimunculkan pun beragam, yaitu 
meningkatkan eksistensi, menguatkan engagement, membantu penjualan, dan menambah jumlah traffic. Peran konten media sosial instagram @ wearedollies dalam pemasaran produk Dollies.

\subsection{Meningkatkan Eksistensi Akun@ @earedollies}

Eksistensi memiliki makna sebagai perwujudan atau keberadaan dengan memiliki tingkat ketenaran tertentu dari Dollies sebagai sebuah online shop melalui akun instagram @ wearedollies. Dalam hal konten media sosial instagram @wearedollies, peran utama yang dirasakan dalam pemasaran produk Dollies menurut pemilik Dollies adalah eksistensi. Menurut pemilik Dollies, eksistensi di media sosial sangat diperlukan karena memiliki jangkauan konsumen yang lebih luas dibandingkan menjalankan bisnis secara konvensional.

"Pertama, kan awalnya di bandung aja, buka toko di ruko Metro Indah Mall, berarti konsumennya hanya orang bandung aja, setelah itu masuk deh ke ecommerce, kan kalo kita di ecommerce, konsumennya bisa mencakup se- Indonesia ya. Analoginya, bandung misalnya total masyarakatnya $7 j$ torang, ketika kita bisa menjangkau 200jt orang maka potensinya bisa lebih besar lagi. Dan tidak perlu effort yang lebih ketika main di ecommerce shopee. Nah, kalo instagram sendiri ya perannya sebagai media komunikasi pemasaran buat nunjukkin kita jualan untuk se-Indonesia” (Sofyana Hambali, pemillik online shop store Dollies)

Berdasarkan hasil observasi peneliti saat mengunjungi online shop store Dollies menunjukkan bahwa eksistensi Dollies memang terlihat dari jumlah 693 ribu followers. Eksistensi tersebut diperlihatkan dalam bentuk Profil instagram sebagai online shop melalui instagram @ wearedollies.

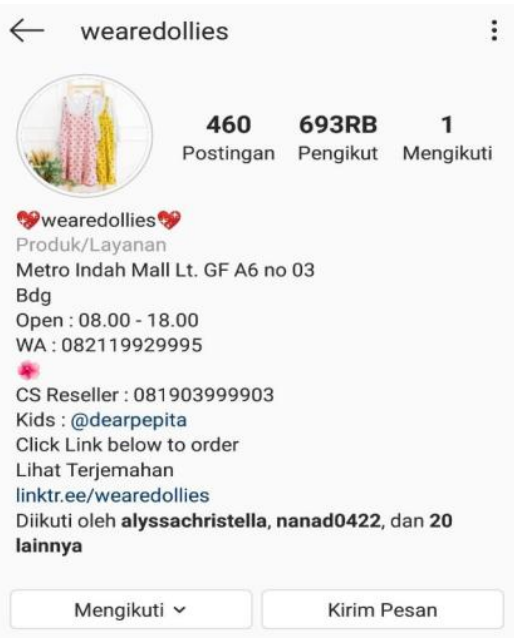

Sumber: Instagram.com/@wearedollies (2019)

Gambar 3. Halaman Profil Instagram @wearedollies

Dalam gambar tersebut termuat foto-foto produk konten foto produk yang dibuat secara model katalog sangat memperhatikan nilai estetika, misalnya, dengan tone foto yang digunakan. Berdasarkan hasil observasi dan dokumentasi peneliti, foto produk dalam bentuk katalog pada feeds instagram @wearedollies menunjukkan bahwa produk Dollies memiliki karakter tersendiri yang tidak terlepas dari estetika yang diciptakan dari proses pembuatan konten.

"Tone foto itu lumayan penting sih, karena kan jadi karakter ya buat merek Dollies sendiri, tetep mesti punya warna dominan gitu buat hampir setiap kontennya. Dollies pakenya pink karena itu warna girly kan, pink nya juga bukan pink yang fanta atau ngejreng gitu tapi ya yang pastel, kalo ada warna lain pun ya warna pastel aja. Untuk katalog produk itu kan 
kadang pake model kadang engga, terus kalo engga juga itu setting backgroundnya mesti beda- beda supaya engga monoton banget. Kalo gitu gitu aja pasti konsumen jenuh liatnya, meskipun barangnya baru, karena backgroundnya itu itu aja nanti bisa disangka barang lama kan yang gak laku-laku, jadi ya gitu sih." (Nurul Faida, manajer pemasaran online shop store Dollies)

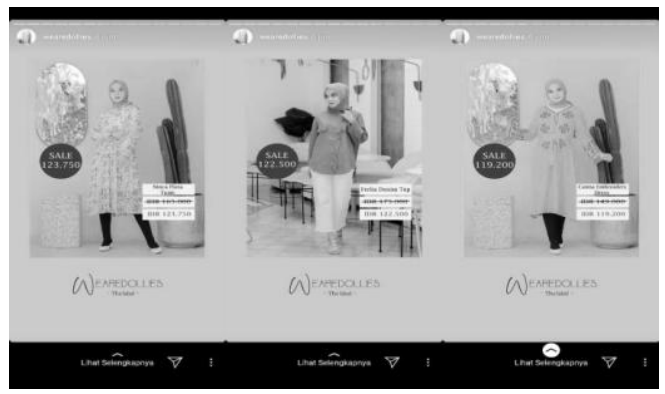

Sumber: Instagram.com/@wearedollies (2019)

Gambar 4. Konten Foto Produk Instagram @ wearedollies

Manajer Pemasaran Dollies mengungkapkan bahwa konsep foto yang digunakan adalah untuk memberi kesan hidup yang berujung pada penguatan eksistensi instagram @ wearedollies.

"Ya sama, supaya hidup, aktif gitu. Makanya kalo yang foto produk di feeds ig gitu kan konsepnya kita ganti-ganti supaya dinamis, jadi hidup gitu. Untuk isi kontennya sendiri ya paling posting foto produk, di repost lagi di hari besokannya", (Nurul Faida, manajer pemasaran online shop store Dollies)

Selain itu, foto produk juga dipublikasikan melalui fitur instastory untuk semakin memicu menunjukkan eksistensinya. Oleh sebab itu, karena foto produk yang dipublikasi memiliki peran penting bagi eksistensi Dollies melalui instagram @ wearedollies, konten tersebut memiliki intensitas paling tinggi untuk dimuat dalam instagram @ wearedollies. Hal tersebut diungkapkan oleh pemilik Dollies. Begitupun Manajer Pemasaran Dollies yang berkontribusi dalam eksekusi pembuatan konten media sosial instagram @wearedollies mengungkapkan hal demikian.

"Produk baru biasanya di posting setiap hari senin, seminggu kita bisa ada 70 model baru. Gamungkin kan kita posting sekaligus, jadi bertahap gitu dari senin sampe rabu”, (Nurul Faida, manajer pemasaran online shop store Dollies)

Selain itu, video produk memiliki peran bagi eksistensi Dollies sebagai online shop melalui instagram @wearedollies. Salah satu faktor pemicu eksistensi yang berperan dari instagram @ wearedollies adalah konten video produk. Hal tersebut terjadi pada saat instagram @ wearedollies melakukan publisitas produknya dalam bentuk videodi instagram, seperti yang ditemukan dari hasil observasi dan dokumentasi peneliti sebagai berikut.

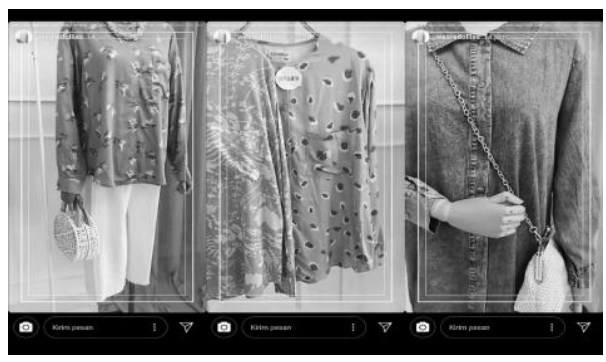

Sumber: Instagram.com/@wearedollies (2019)

Gambar 5. Konten Video Produk pada Instagram @ wearedollies 
Konten video produk dikemas dengan melakukan mengulas produk yang dijual, seperti yang dijelaskan oleh pemilik Dollies berikut. Manajer Pemasaran Dollies yang turut berkontribusi dalam pembuatan konten ini juga menyatakan hal serupa dan menambahkan argumentasi bahwa video produk tersebut bertujuan agar instagram @ wearedollies lebih hidup sehingga dapat menjaga eksistensi. Oleh sebab itu, konten video produk merupakan konten yang intensitasnya cukup tinggi yang dimuat dalam instagram @ wearedolies.

"Video juga gitu, biasanya di story ig kita ngereview produk gitu, saya mc nya, ngejelasin bahan, warna gitu supaya hidup. Kalo cuma bener-bener foto aja kan, kurang hidup sih, nanti kurang eksis.", (Nurul Faida, manajer pemasaran online shop store Dollies)

\subsection{Caption Informatif}

Caption memiliki peran bagi eksistensi Dollies sebagai online shop melalui instagram @wearedollies. Salah satu faktor pemicu eksistensi yang berperan dari instagram @wearedollies adalah penggunaan caption. Hal tersebut terjadi pada saat instagram @wearedollies menuliskan caption atau keterangan dalam setiap postingan produknya pada feeds instagram @wearedollies. Caption merupakan konten berupa teks yang disediakan sebagai fitur oleh instagram. Hal tersebut dimanfaatkan Dollies untuk memberikan informasi mengenai keterangan produk yang dijual Dollies melalui instagram @wearedollies. Spesifikasi informasi yang dimuat pada caption yang dimuat pada konten instagram @ wearedollies adalah nama produk, harga, ukuran, bahan, warna, dan cara melakukan pemesanan. Hasil observasi tersebut juga sejalan dengan yang diungkapkan oleh pemilik Dollies.

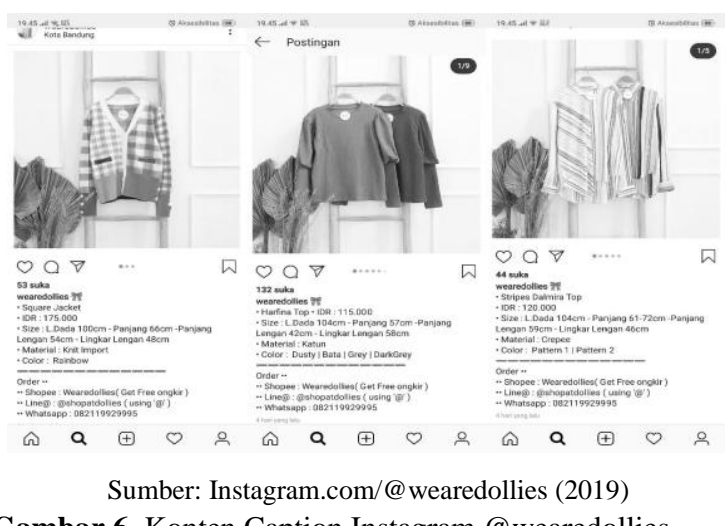

Gambar 6. Konten Caption Instagram @ wearedollies

Pemilik Dollies juga mengungkapkan bahwa caption yang dimuat pada setiap konten feeds instagram @wearedollies tidak menggunakan hashtag.

“...Jadi pada tau kan bahannya, varian warnanya, terus di caption juga kan nanti ada keterangan gimana ordernya. Kalo dalam bentuk textnya paling di caption kan, kita gak pake hashtag karena emang maksimalin followers yang udah ada aja target konsumennya. Foto produk udah sama caption terus sama review produk juga, karena itu kan yang paling berperan buat eksistensi Dollies sebagai online shop", (Sofyana Hambali, pemillik online shop store Dollies)

Oleh sebab itu, caption sebagai konten bermuatan teks menjadi yang paling sering dimuat dalam instagram @wearedollies seiring dengan setiap postingan pada feeds instagram @wearedollies yang dipublikasikan. Hal ini diungkapkan Manajer Pemasaran Dollies bahwa caption berperan dalam eksistensi Dollies sebagai online shop. 


\subsection{Feedback Komentar}

Feedback komentar memiliki peran bagi eksistensi Dollies sebagai online shop melalui instagram @wearedollies. Salah satu faktor pemicu eksistensi yang berperan dari instagram @ wearedollies adalah keaktifan merespons customer di kolom komentar. Hal tersebut terjadi pada saat instagram@wearedollies menuliskan balasan komenter yang ada dalam setiap postingan produknya pada feeds instagram @ wearedollies, seperti yang ditemukan dari hasil observasi dan dokumentasi peneliti sebagai berikut.

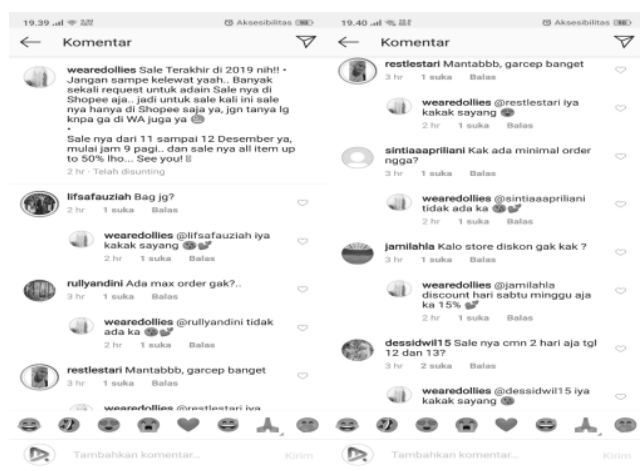

Sumber: Instagram.com/@ wearedollies (2019)

Gambar 7. Konten Feedback Komentar Instagram @ wearedollies

Feedback komentar merupakan konten berupa teks yang disediakan sebagai fitur oleh instagram. Hal tersebut dimanfaatkan Dollies untuk melakukan interaksi terhadap pertanyaan customer yang muncul di kolom komentar mengenai produk yang dijual Dollies melalui instagram @wearedollies. Spesifikasi informasi yang dimuat pada feedback komentar yang dimuat oleh admin instagram @wearedollies adalah jawaban dari pertanyaan customer, dan sebagainya. Hasil observasi tersebut juga sejalan dengan yang diungkapkan oleh pemilik Dollies.

"komen IG itu penting ya buat aktivitas di instagram, apalagi komen, kalo misal ada respons dari customer di komentar ig, terus kita gak bales, mereka bisa mikir kita ini gak serius kan jalanin bisnis, gak profesional. Makanya mesti aktif juga ngasih feedback komentarnya customer supaya keliatan ada, kita profesional, punya admin buat balesin respon customer. Ya, ujungnya kaya yang tadi, eksistensi atau keberadaan kita sebagai online shop jadi bagus gitu." (Sofyana Hambali, pemillik online shop store Dollies)

Manajer Pemasaran Dollies pun mengungkapkan urgensi eksistensi yang harus dimunculkan Dollies melalui instagram @ wearedollies dengan memberikan tanggapan pada komentar customer menjadikan hal tersebut sebagai aktivitas rutin dalam bentuk konten teks. Hal tersebut juga dibenarkan oleh pemilik Dollies yang menghendaki admin instagram @ wearedollies untuk aktif dalam kolom komentar instagram @ wearedollies karena hal tersebut dinilai penting untuk masukan terhadap Dollies. Dengan begitu, respons customer terhadap Dollies akan bertahan pada kecenderungan yang positif.

"Respons customer beragam ada yg mengkritik ada juga yg memberikan saran, kadang dengan cara komen langsung di postingan atau bahkan ada yg langsung dm, tapi seringan sih di shopee langsung. Makanya admin kita aktif di ig nanggapin respon customer baik itu kritikan atau saran akan banyak yg tertarik untuk order ke kita karena dapat di bilang kita ramah selalu bertanggung jawab terhadap customer. Tapi ya kebanyakan positif sih, bisa cek aja di shopee.", (Sofyana Hambali, pemillik online shop store Dollies) 


\subsection{Direct Message Interaktif}

Direct message memiliki peran bagi eksistensi Dollies sebagai online shop melalui instagram $@$ @earedollies. Salah satu faktor pemicu eksistensi yang berperan dari instagram @ wearedollies adalah keaktifan merespons customer di direct message. Hal tersebut terjadi pada saat instagram @ wearedollies menuliskan balasan pesan yang ada dalam setiap direct message yang masuk, seperti yang ditemukan dari hasil observasi dan dokumentasi peneliti sebagai berikut.

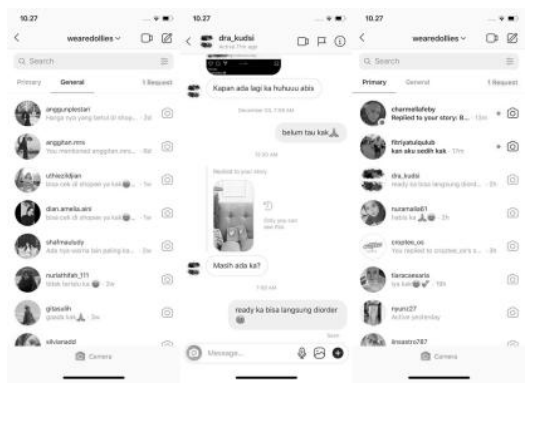

Sumber: Instagram.com/@wearedollies (2019)

Gambar 8. Konten Direct Message Instagram @ wearedollies

Pemilik Dollies mengungkapkan bahwa konten berupa teks yang dimuat instagram @wearedollies melalui pemanfaatan fitur direct message yang dimiliki instagram, memiliki peran penting bagi eksistensi@wearedollies sebagai online shop sehingga hal tersebut menjadi aktivitas rutin yang dilakukaninstagram@wearedollies.

"Kalo aktivitas sendiri selain bikin konten ya interaksi, lewat dm gitu, karena kan eksistensi Dollies juga ada di interaksi yang kaya gitu", (Sofyana Hambali, pemillik online shop store Dollies)

Pemilik Dollies juga menyiapkan admin instagram untuk selalu aktif dalam setiap publikasi konten, terutama dalam hal interaksi dengan customer melalui direct message yang dinilai memiliki peran eksistensi.

"Interaksi intensif, admin standby buat balesin komen ig sama dm yang masuk, terus di shopee dan whatsapp juga sama. Harus responsive, soalnya itu penting banget buat nunjukkin dollies itu ada, serius, bukan olshop asal-asalan.", (Sofyana Hambali, pemillik online shop store Dollies)

Direct message juga diyakini Manajer Pemasaran Dollies sebagai konten teks yang memiliki peranan dalam eksistensi @ wearedollies sebagai online shop yang bagus.

"Kalo engga informatif sama engga fast respons gitu pasti customer mikirnya kita ini olshop abal-abal kan, dikira gak ada adminnya gitu. Makanya mesti kaya gitu biar jelas aja kalo Dollies tuh aktif kok, online shop bagus, profesional. Jadi, ya bener-bener diperhitungkan keberadaannya.", (Nurul Faida, manajer pemasaran online shop store Dollies)

\subsection{Menguatkan Engagement}

Engagement, memiliki makna sebagai hubungan erat yang terjalin melalui interaksi yang intensif dan memikat. Dalam hal ini konten media sosial instagram @ wearedollies mengkreasikan konten yang berperan dalam pemasaran produk Dollies karena memiliki engagemet yang kuat antara @wearedollies dengan customer. Manajer Pemasaran Dollies mengungkapkan bahwa beberapa 
konten memiliki peran sebagai penguat engagement antara @wearedollies dan customer agar tidak hanya sekadar berhubungan sebagai antara penjual dan pembeli.

"Jadi, engga cuma sekedar penjual pembeli, tapi ada hubungan lebih yang lebih erat. Ini penting buat ngejaga customer, supaya ada repeat order karena udah erat banget nih hubungan customer ke Dollies.", (Nurul Faida, manajer pemasaran online shop store Dollies)

Adapun konten meda sosial sebagai 78nstrument yang memiliki peran engagement bagi Dollies dalam pemasaran produk melalui instagram @ wearedollies, yaitu sebagai berikut.

\subsection{Repost Foto Customer}

Repost atau melakukan posting ulang dari customer yang melakukan posting dengan tagged terhadap instagram@wearedollies memiliki peran bagi penguatan engagement antara Dollies melalui instagram@wearedollies dengan customer. Berdasarkan hasil observasi peneliti, sebelum melakukan repost instagram @wearedollies membuat konten informasi terlebih dahulu agar para customer melakukan posting foto dengan tagged menggunakan produk Dollies.

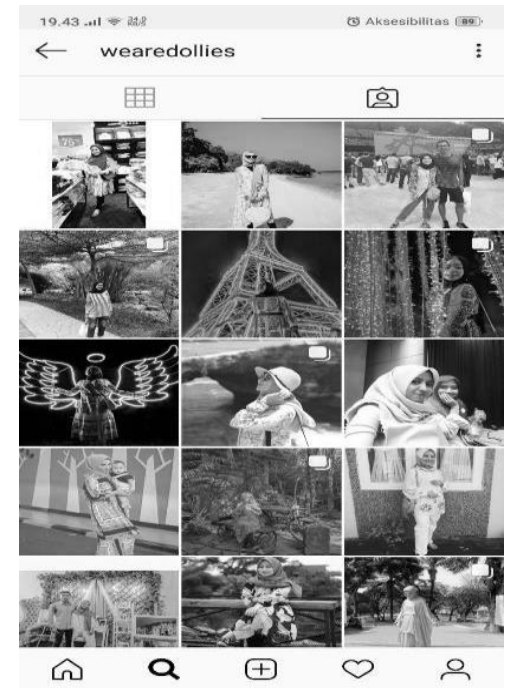

Sumber: Instagram.com/@ wearedollies (2019)

Gambar 9. Konten Repost Instagram @wearedollies

Setelah itu, instagram @wearedollies akan menyeleksi berdasarkan tagged foto yang masuk. Foto terbaik akan mendapatkan repost serta hadiah dari Dollies. Dengan begitu, engagement antara Dollies dan customer akan menguat. Repost dilakukan dalam feeds instagram @wearedollies, seperti yang ditemukan pada hasil observasi dan dokumentasi berikut ini.

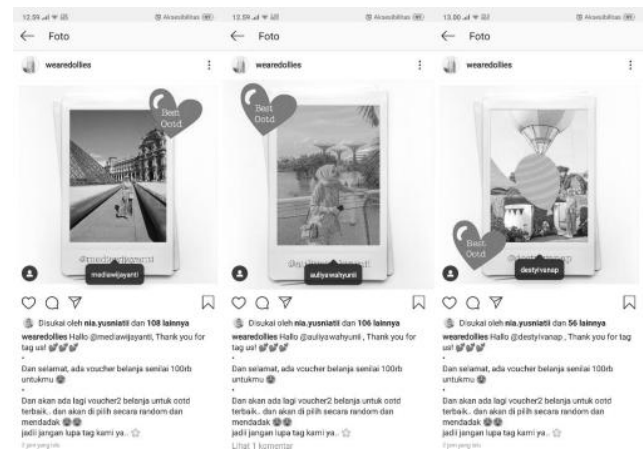

Sumber: Instagram.com/@wearedollies (2019)

Gambar 10 . Konten Repost pada Feeds Instagram @ wearedollies 
Konten repost yang dilakukan instagram @ wearedollies memuat konten berisi foto dari customer yang melakukan tagged dengan instagram @ wearedollies. Selain pada feeds instagram, @ wearedollies juga memuat konten tersebut melalui fitur instagram story sehingga jangkauan yang dihasilkan lebih maksimal, seperti hasil observasi dan dokumentasi berikut ini. Dengan konten repost seperti itu, pemilik Dollies mengungkapkan bahwa konten tersebut berperan untuk engagement antara Dollies dan customer.

“Kita juga sukangerepost yang tagged@wearedollies sama repost di instastory kalo ada testimoni gitu ya tujuannya biar nambahin trust dan engagement aja gitu kan, ya variasi konten lah daripada gitu-gitu aja. Ini aja repost-repost tetep gitu-gitu aja", (Sofyana Hambali, pemillik online shop store Dollies)

\subsection{Publikasi Testimoni Customer}

Testimoni adalah kesaksian kepuasan yang dirasakan oleh customer, biasanya testimoni tersebut dipublikasi oleh customer dengan cara melakukan posting baik foto ataupun video dengan tagged ke instagram @wearedollies. Setelah itu, instagram @wearedollies akan melakukan posting ulang testimoni tersebut sebagai konten testimoni Dollies melalui instagram @wearedollies. Berdasarkan hasil observasi dan dokumentasi, konten testimoni dimuat dalam instagram story $@$ wearedollies seperti berikut ini.

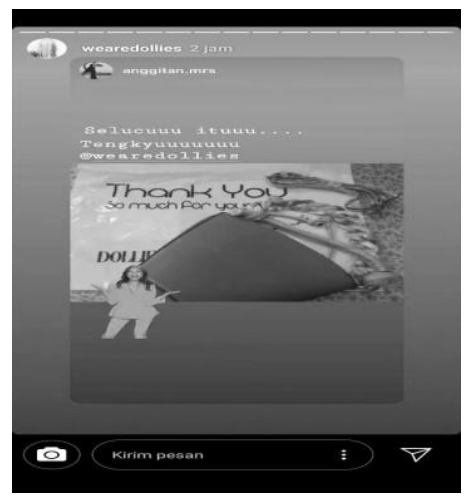

Sumber: Instagram.com/@wearedollies (2019)

Gambar 11. Konten Testimoni Instagram @ wearedollies

Konten testimoni memiliki peran sebagai penguat engagement antara Dollies melalui instagram @wearedollies dengan customernya seperti yang diungkapkan oleh Manajer Pemasaran Dollies.

"Hmm paling kalo repost sama testimoni itu ya supaya ada hubungan positif aja yang dirasain customer ke Dollies. ”, (Nurul Faida, manajer pemasaran online shop store Dollies)

Pemilik Dollies mengungkapan bahwa testimoni yang diberikan customer ada yang negatif meskipun cenderung positif.

"Testimoni customer juga ada yang bagus ada yang engga, paling gampang bisa dilihat di shopee aja kan ada analitik performa toko tuh ya, bintangnya 4,7 ya masih oke gitu kan, bisa nanti di screenshot aja. Bisa jadi representasi kan daripada repot-repot cek komen satu per satu.", (Sofyana Hambali, pemillik online shop store Dollies) 


\subsection{Pemberian Diskon}

Diskon atau potongan harga merupakan salah satu konsep konten yang dimuat instagram $@$ wearedollies sebagai peranan dalam penjualan produk Dollies. Dengan adanya konten diskon di hari tertentu, pemilik Dollies menyatakan bahwa hal tersebut berperan dalam penjualan produk Dollies melalui instagram@wearedollies.

“...suka ngasih diskon di hari-hari tertentu karena itu nanti ngefek buat penjualan.” (Sofyana Hambali, pemillik online shop store Dollies)

Hal tersebut juga diucapkan oleh Manajer Pemasaran Dollies yang beranggapan bahwa konten diskon memiliki peran terhadap penjualan produk Dollies.

"Paling info diskon apalagi mau harbolnas gini kan, semua toko juga pada ngasih diskon, sama kalo misalnya udah akhir bulan, kita kasih diskon, karena nyesuain keuangan customer dan supaya barang kita juga habis kan hehe”. (Nurul Faida, manajer pemasaran online shop store Dollies)

Berikut ini merupakan hasil observasi dan dokumentasi yang peneliti temukan dari konten diskon pada instagram @wearedollies.

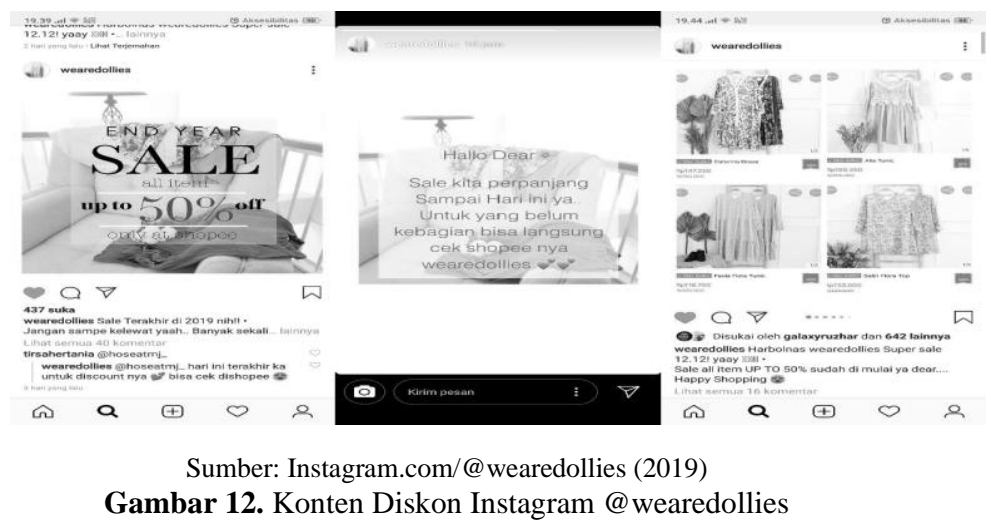

Manajer Pemasaran Dollies juga menjelaskan bahwa konten diskon memang berperan dalam penjualan produk Dollies, tetapi cenderung hanya berdasarkan kuantitas bukan secara margin laba.

“...tapi ya itu paling secara kuantitas, secara hitungan laba kayanya engga terlalu berperan deh. Tapi kan gapapa, daripada barang gak keluar malah jadi beban kan”. (Nurul Faida, manajer pemasaran online shop store Dollies)

\subsection{Penggunaan Endorser}

Endorse merupakan periklanan yang dilakukan dengan menggunakan influencer, baik itu artis, selebgram, maupun yang lainnya. Konten instagram @wearedollies memuat periklanan dengan konsep tersebut. Pemilik Dollies mengungkapkan bahwa konten endorse pada instagram $@$ wearedollies dilakukan dengan cara mem-posting ulang endorse yang dilakukan oleh influencer tertentu.

“...Ya, paling kan kita minta influencer itu review produk Dollies dulu kan, terus tagged ig kita, baru abis itu kita repost”. (Sofyana Hambali, pemillik online shop store Dollies)

Pemilik Dollies juga mengungkapkan bahwa konten endorse tidak berperan signifikan dalam penjualan tetapi berperan dalam traffic customer pada instagram @ wearedollies melalui brand 
awareness yang dimunculkan serta peningkatan followers instagram @ wearedollies bahkan lebih besar menjangkau konsomen daripada menggunakan ads instagram.

"...Secara peranan sih konten dari endorser itu tidak signifikan mempengaruhi penjualan, kalo yang lainnya mungkin iya, kaya misalnya brand awareness, followers Instagram, dsb”. (Sofyana Hambali, pemillik online shop store Dollies)

“...Nge buzz pernah pake iklan, itu efeknya minim banget, nambah followers juga dikit. Paling banyak ya pake endorser, bisa nambahin followers gitu...”. (Sofyana Hambali, pemillik online shop store Dollies)

Hal tersebut juga diungkapkan oleh Manajer Pemasaran Dollies bahwa konten endorse berperan dalam peningkatan traffic customer pada instagram @ wearedollies.

"Endorse penting banget buat nambahin followers, efek kedepannya juga kan pas followers banyak, customer jadi trust kan, awareness nya juga tinggi, meskipun gak ngejamin pada beli nih. Tapi kan lumayan buat traffic ig. "(Nurul Faida, manajer pemasaran online shop store Dollies)

Selain itu, Pemilik Dollies juga mengungkapkan bahwa konten endorse dapat melibatkan customer secara lebih interaktif kepada instagram @wearedollies.

“...ada artis endorse gitu juga customer jadi aktif di interaksinya ke kita. Paling itu aja sih yang paling keliatan efeknya buat ningkatin traffic ig dollies."(Sofyana Hambali, pemillik online shop store Dollies)

Pemilik Dollies menyatakan bahwa Dollies pernah menggunakan beberapa influencer seperti artis dan selebgram dalam konten endorse, meskipun hal tersebut tidak berperan signifikan pada penjualan tetapi sangat berperan dalam traffic yang diberikan.

“...Iya pernah pake endorser. Endorser pernah pakai Rachel Venya, Ria Ricis, Luna Maya, Ola Ramlan, terus Jessica Iskandar, ga ngaruh banget itu ke penjualan haha. Tasya Farasya juga udah pernah, ya maksudnya ngaruh tapi tidak signifikan. Tanpa pakai selebgram, sebenernya penjualan tetep ada. Dia cuma nambah followers itu juga sejauh ini yang paling banyak itu yang dari Rachel Venya... "(Sofyana Hambali, pemillik online shop store Dollies)

Hasil observasi dan dokumentasi menemukan konten endorse yang dimuat dalam instagram @ wearedollies dengan Influencer yang terlibat adalah Jessica Iskandar, Ashry Rabbani, Nabila Zirus seperti berikut.
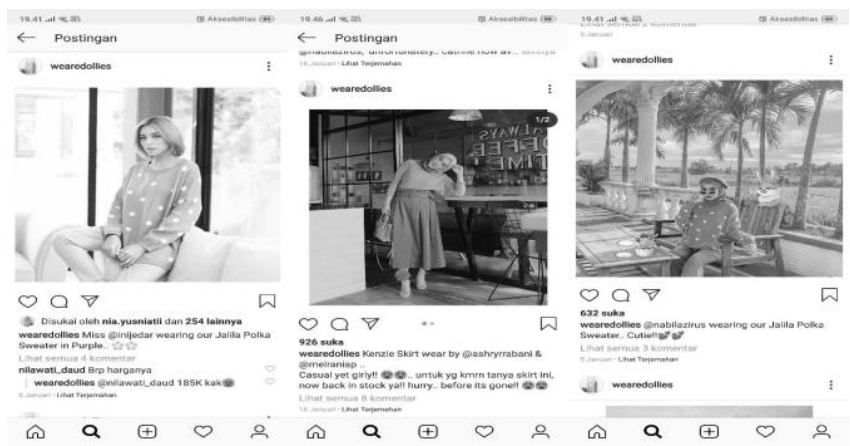

Sumber: Instagram.com/@ wearedollies (2019)

Gambar 13. Konten Endorse Artis pada Instagram @ wearedollies 
Alasan pemilik Dollies menggunakan endorser pada saat itu adalah untuk meningkatkan traffic melalui penambahan followers instagram @ wearedollies.

“...Alasan waktu itu pake endorser karena melihat perkembangan jumlah followers yang ga naik naik, sekarang malah turun kan, karena udah lama gapake endorser” (Nurul Faida, manajer pemasaran online shop store Dollies)

Meskipun memiliki peran positif dalam meningkatkan traffic, konten endorse tidak sering dilakukan karena membutuhkan alokasi dana yang besar dan juga tidak berperan signifikan terhadap penjualan yang menjadi target utama Dollies melakukan pemasaran produk Dollies.

“...Tetapi pada tolak ukur sebagai owner itu kan ya penjualan kan. Kaya misalnya, waktu itu pernah endorse kan pakai luna maya, habis sampai 10 juta kalo ga salah, bayar Rachel Vennya 5 juta, followers sih ya nambah ya tapi kalo untuk penjualan itu sendiri kekuatannya tetep ada di produk gitu. Makanya mending kuatin di formula produk hehe. Disesuaikan dengan minat pasar, jangan pakai persepsi pribadi kalo jual barang" (Sofyana Hambali, pemillik online shop store Dollies)

“...Paling banyak ya pake endorser, bisa nambahin followers gitu tapi kan ya mahal, gak bisa sering-sering kita konten pake endorser"(Sofyana Hambali, pemillik online shop store Dollies)

Hal tersebut juga serupa dengan yang diungkapkan oleh Manajer Pemasaran Dollies bahwa biaya untuk endorse yang besar menjadikan konten endorse pada instagram @ wearedollies tidak sering dilakukan.

“...Kalo lagi banyak dana untuk alokasi traffic ig, baru tuh pake endorse, ke artis, selebgram segala macem supaya ada traffic banyak ke ig dollies. Nah, makanya sekarang followers nya bisa banyak gitu ya karena konten yang kaya gitu". (Nurul Faida, manajer pemasaran online shop store Dollies)

\subsection{Kegiatan Giveaway}

Giveaway merupakan kegiatan berbagi hadiah dengan persyaratan, kondisi, dan ketentuan tertentu. Dollies meliliki konten giveaway seperti hasil observasi dan dokumentasi sebagai berikut.

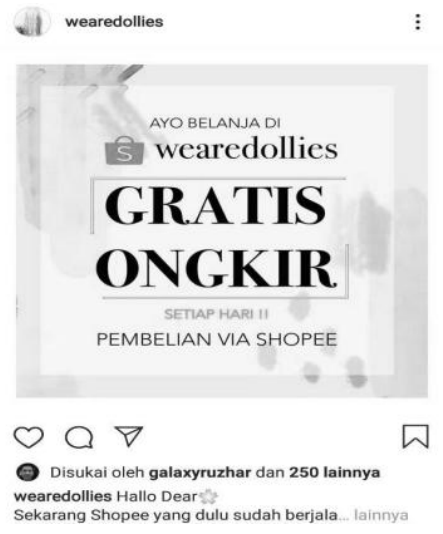

Sumber: Instagram.com/@ wearedollies (2019)

Gambar 14. Konten Giveaway pada Feeds Instagram @ wearedollies 
Konten giveaway yang digunakan Dollies memiliki beragam konsep, seperti gratis ongkir, spam like, dan sebagainya tetapi tidak sering dilakukan bahkan Manajer Pemasaran Dollies mengungkapkan terakhir kali konten giveaway dilakukan adalah sebelum lebaran.

“...terus suka ada giveaway juga tapi itu terakhir sih sebelum lebaran...” (Nurul Faida, manajer pemasaran online shop store Dollies)

"Kalo giveaway kan tadi ya, udah lama gak bikin, terakhir itu sebelum lebaran..."(Nurul Faida, manajer pemasaran online shop store Dollies)

Manajer Pemasaran Dollies juga beranggapan bahwa konten giveaway memiliki peran positif untuk peningkatan traffic instagram @wearedollies. Pernyataan Manajer Pemasaran Dollies tersebut seiring dengan penelitian Afrilia (2018) dan Amanda, P.S., Baihaqi, I. dan Persada (2017), peningkatan traffic media sosial seperti Instagram memang memilki dampak yang maksimal sebagai sarana proses digital marketing saat ini. Eksistensi Dollies sebagai online shop yang dikomunikasikan melalui instagram @ wearedollies turut mengubah citra Dollies secara awareness terhadap merek produk. Selain itu, pemilik Dollies juga menilai kuatnya peran eksistensi @wearedollies juga memudahkan penerimaan persepsi konsumen dalam memahami karakter dari produk-produk Dollies terutama ketika menyesuaikan segmentasi konsumen. Dollies memiliki karakter produk sebagai import clothes seperti yang dimunculkan pada konten bio instagram @wearedollies sebelumnya, kemudian seiring dengan penyesuaian segmentasi konsumen, keterangan tersebut dihilangkan agar awareness tentang import clothes tersebut lepas dari eksistensi merek Dollies yang kini menyasar konsumen muslimah atau jilbabers. Hal tersebut juga terjadi dengan perubahan nama merek dan logo Dollies menjadi Wearedollies seperti saat ini. Berdasarkan hal tersebut, konten profil instagram tergolong pada bauran promosi public relations, karena memiliki fungsi publisitas toko dan produk sebagaimana definisi public relations menurut Kotler dan Keller (2012), bahwa hubungan masyarakat atau publisitas, yaitu ragam kegiatan atau suatu program yang dirancang perusahaan guna mempromosikan dan melindungi citra perusahaan dan produk individunya. Sehingga konten profil instagram dapat berperan untuk eksistensi Dollies dalam pemasaran produknya melalui instagram @ wearedollies.

Foto katalog produk juga memiliki peran bagi eksistensi Dollies sebagai online shop melalui instagram@wearedollies. Vassallo et al. (2018) mengatakan semakin banyak jumlah frekuensi yang tinggi dalam posting beragam foto-foto katalog produk, akan semakin mengakselerasi memori tentang branding bagi konsumen. Eksistensi tersebut kemudian menjadi pemicu munculnya sisi keunikan produk Dollies di instagram @wearedollies. Hal tersebut terjadi pada saat instagram @wearedollies melakukan publisitas produknya dalam bentuk foto di instagram. Selain itu, konten foto produk yang dibuat secara model katalog sangat memperhatikan nilai estetika, misalnya dengan tone foto yang digunakan, dan lainnya.Sales atau penjualan merupakan tujuan akhir dan utama dari pemasaran yang dilakukan Dollies, salah satu instrumennya adalah instagram @wearedollies sebagai media komunikasi pemasaran. Meskipun begitu, pemilik Dollies masih menilai bahwa konten di instagram @wearedollies tidak banyak yang signifikan berperan dalam penjualan sebagai tujuan akhir aktivitas pemasaran produk Dollies. Pemilik Dollies juga mengungkapkan bahwa yang paling berperan dalam media penjualan adalah Shopee dan Whatsapp, bukan instagram. Pemilik Dollies menilai bahwa hal yang paling berperan signifikan dalam penjualan produk Dollies adalah fokus terhadap produk, bukan pada promosi seperti yang sudah dilakukan melalui instagram @wearedollies. Oleh sebab itu, dalam melakukan pemasaran yang berfokus utama pada target penjualan, Pemilik Dollies lebih berkonsentrasi pada produk, tidak terlalu fokus pada konten instagram @ wearedollies. Saat ini, Dollies masih melakukan formulasi 
terhadap produk sebagai bentuk konsentrasinya dalam target penjualan. Sehingga terbentuklah formula sementara untuk produk yang dijual Dollies adalah 20\% produk lokal, $40 \%$ produk impor, dan $40 \%$ produk makloon. Hal tersebut tidak terlepas dari fokus pengembangan produk mengikuti keinginan pasar untuk pencapaian target penjualan. Urgensi formulasi produk yang akhirnya memasukkan produk makloon juga didasari oleh permintaan Shopee sebagai marketplace yang dinilai paling berperan dalam penjualan Dollies menginginkan Dollies melakukan produksi mandiri. Dengan begitu, keunikan produk Dollies juga akan lebih kuat dan berperan terhadap penjualan. Alasan lain yang diungkapkan Pemilik Dollies mengenai penggunaan konsep makloon terhadap formulasi produknya adalah untuk mendapatkan margin laba yang lebih besar dari penjualan yang dilakukan. Dengan memfokuskan pada formulasi produk yang disesuaikan dengan keinginan pasar dan pemanfaatan marketplace Shopee sebagai hal yang paling berperan dalam penjualan Dollies maka akan lebih memudahkan Dollies dalam mencapai target penjualan.

\section{PENUTUP}

Berdasarkan hasil penelitian mengenai peran konten media sosial Instagram dalam pemasaran produk Dollies adalah Konten media sosial instagram @wearedollies berperan sebagai eksistensi produk, engagement, sales, dan traffic dalam pemasaran produk Dollies melalui instagram @ wearedollies dengan rincian pada konten profil instagram, foto produk, video produk, caption, feedback komentar, dan direct message; Strategi Engagement terdapat pada konten repost dan testimony. Sedangkan strategi sales terdapat pada konten open reseller, discount, dan open order. Strategi terakhir adalah traffic yang terletak pada konten endorse dan giveaway. Konten media sosial instagram@wearedollies juga menggunakan seluruh unit bauran promosi, yaitu public relations, sales promotion, personal promotion, mouth to mouth, direct promotion, dan advertising dengan rincian sebagai berikut: Public relations, terdapat pada konten profil instagram, foto produk, video produk, dan open reseller; Sales promotion, terdapat pada konten discount dan giveaway; Personal promotion, terdapat pada konten caption, feedback komentar, dan direct message; Mouth to mouth, terdapat pada konten repost dan testimoni; Direct promotion, terdapat pada konten open order; Advertising, terdapat pada konten endorse.-Selain itu, Dollies melakukan kombinasi bauran pemasaran $4 \mathrm{P}$, yaitu product, price, place, dan promotion dengan pola IMC (Integrated Marketing Communication), yaitu berfokus utama pada formulasi produk dan harga serta optimalisasi marketplace, sedangkan promosi dilakukan dengan menggunakan instagram melalui konten-kontennya sebagai media komunikasi pemasaran untuk membangun customer relationship.

\section{Ucapan Terima Kasih}

Penulis menyampaikan ucapan terima kasih kepada yaitu Sofyana Hambali., S.M., M.B.A sebagai pemilik Dollies@ @earedollies, Nurul Faida sebagai Manajer Pemasaran konten media sosial Instagram @ wearedollies, Dr. Mohamad Toha, S.T., M.B.A sebagai informan pakar strategi berbisnis dan para reviewer Jurnal Studi Komunikasi dan Media yang telah memberikan masukanmasukan yang komprehensif.

\section{DAFTAR PUSTAKA}

Afrilia, A. M. (2018). Digital Marketing sebagai Strategi Komunikasi Pemasaran "Waroenk Ora Umum" dalam Meningkatkan Jumlah Konsumen. Jurnal Riset Komunikasi, 1(1), 147-157.

Amanda, P. S., Baihaqi, I., \& Persada, S. F. (2017). Pengaruh Konten Post Instagram terhadap Online Engagement: Studi Kasus pada Lima Merek Pakaian Wanita. Jurnal Teknik ITS, 6(1), 217-221.

Andika, D. R., \& Jovita, C. (2018). Media Sosial Instagram sebagai Sarana Promosi untuk Meningkatkan 
Minat Beli. Jurnal Bisnis Terapan, 1(1), 25-32.

Asanbekova, M., \& Maksudunov, A. (2018). The Marketing Power of Instagram: A Content Analysis of Top Hotel Enterprises in Kyrgyzstan. International Journal Turkey: Uluslararasi Turk Dunyasi Turizm Arastirmalan Dergisi, 3(2), 141-152.

Evans, D. (2012). Social Media Marketing - An Hour a Day. John Willey \& Sons, Inc.

Fauzi, D. H., \& Mileva, L. (2018). Pengaruh Social Media Marketing terhadap Keputusan Pembelian. Jurnal Administrasi Bisnis, 58(1), 190-199.

Germon, R., Sokolova, K., \& Bami, A. (2017). Analyzing User Generated Content on Instagram: The Case of Travel Agencies. The Ninth International Conferences on Pervasive Patterns and Applications, 78-81.

Nadya. (2016). Peran Digital Marketing dalam Eksistensi Bisnis Kuliner Seblak Jeletet Murni. Jurnal Riset Manajemen Dan Bisnis, 1(2), 133-144.

Shuqair, S., \& Cragg, P. (2016). The Immediate Impact of Instagram Posts on Changing The Viewers Perceptions Towards Travel Destinations. Asia Pasific Journal of Advanced Business and Social Studies, 3(2), 1-12.

Sugiyono. (2017). Metode Penelitian Kuantitatif, Kualitatif dan R\&D. Alfabeta.

Taiminen, H. M., \& Karjaluotom, H. (2015). The Usage of Digital Marketing Channels in SMEs. Journal of Small Business and Enterprise Development, 22(4), 633-651.

Vassallo, A. J., Kelly, B., Zhang, L., Wang, Z., Young, S., \& Freeman, B. (2018). Junk Food Marketing on Instagram: Content Analysis. JMIR Public Health Surveill, 4(2), 54-60. 